\title{
Ticks feeding on ruminants and humans in Greece
}

\author{
I Chaligiannis ${ }^{1,2,3^{*}}$, A Papa $^{3}$, S Sotiraki ${ }^{2}$ \\ From The 1st Conference on Neglected Vectors and Vector-Borne Diseases (EurNegVec): with Management \\ Committee and Working Group Meetings of the COST Action TD1303 \\ Cluj-Napoca, Romania. 8-11 April 2014
}

Ticks are important vectors of disease and transmit an extensive range of viral, bacterial and protozoan pathogens to livestock in a wide variety of habitats. In recent years, diseases such as babesiosis, ehrlichiosis and anaplasmosis have all shown evidence of increased prevalence and distribution in various parts of Europe. However data concerning the prevalence of ticks and tick borne diseases present in livestock and humans in Greece are limited.

In order to fill this gap we performed the current study to define the existence and prevalence of different tick species found in farm animals and humans. As regards livestock, we focused on ruminants (mainly sheep and goats and, in a lesser extent, cattle) since they are the only ones spend time on pastures. A sufficient number of farms all over the country were visited during 2 tick seasons (from March to October), taking different habitats and animal density around Greece into account. Ticks collected from humans originated from infected individuals who visited hospitals.

In total, 2676 ticks were collected from 26 different prefectures (mainland and islands) all over Greece.

From those, 1,883 were coming from sheep (1201) and goats (681) and identified as: Rhipicephalus sanguineus 1,216 (64.65\%); R. bursa 495 (26.3\%); R. camicasi 12 (0.6\%); $R$. turanicus 70 (3.7\%); Ixodes ricinus 1 (0.05\%); Dermacentor marginatus 47 (2.5\%); Hyalomma marginatum 5 (0.3\%); H. excavatum 2 (0.1\%), H. dromedarii 31 (1.6\%) H. rufipes 2 (0.1\%); H. impeltatum 1 (0.05\%); and Rhipicephalus nymph $1(0.05 \%)$. More than half $(54.3 \%)$ of the above were found in an altitude of $0-300$ meters, $37.1 \%$ in an altitude of $301-800 \mathrm{~m}$ and $3.2 \%$ in an altitude of $>800 \mathrm{~m}$.

142 ticks originated from cattle and were identified as: R. sanguineus 15 (10.5\%); R. bursa 6 (4.2\%); R. camicasi 5 (3.5\%); R. turanicus 6 (4.2\%); H. marginatum $24.17 \%)$;
H. excavatum 8 (5.6\%); H. dromedarii 67 (47.2\%); H. rufipes 4 (2.8\%); H. impeltatum 1 (0.7\%); H. anatolicum 3 (2.1\%) and H. turanicum 3 (2.1\%).

Finally, 701 ticks were coming from humans and identified as: $R$. sanguineus 562 (80.17\%); R. bursa 23 (3.28\%); $R$. turanicus 34 (4.85\%); R. annulatus $5(0.71 \%) ; H$. marginatum 30 (4.28\%); H. excavatum 2 (0.28\%); H. rufipes 11 (1.57\%); Dermacentor marginatus 2 (0.28\%); Ixodes ricinus 6 (0.85\%); I. gibosus 6 (0.85\%) and Rhipicephalus nymphs $20(2.85 \%)$.

In conclusion, the majority of ticks found in both animal species and humans examined belonged in the Rhipicephalus sanguineus group which is the main vector of Rickettsia conorii, while Hyalomma marginatum, the vectors of CCHF virus, were also present. The above results were more or less anticipated given the climatic conditions of the area, fact that also explains the low prevalence of Ixodes spp.

\section{Authors' details}

'State Veterinary Laboratory of Thrace, Ministry of Rural Development and Food, Komotini 691 00, Greece. ${ }^{2}$ Veterinary Research Institute of Thessaloniki, HAO-Demeter (former NAGREF), Thermi 57001, Thessaloniki, Greece. ${ }^{3} A^{\prime}$

Department of Microbiology, Medical School, Aristotle University of Thessaloniki, Thessaloniki, Greece.

Published: 1 April 2014

doi:10.1186/1756-3305-7-S1-01

Cite this article as: Chaligiannis et al: Ticks feeding on ruminants and humans in Greece. Parasites \& Vectors 2014 7(Suppl 1):01.

\footnotetext{
* Correspondence: halijohn27@hotmail.com

'State Veterinary Laboratory of Thrace, Ministry of Rural Development and

Food, Komotini 691 00, Greece

Full list of author information is available at the end of the article
}

(c) 2014 Chaligiannis et al.; licensee BioMed Central Ltd. This is an Open Access article distributed under the terms of the Creative Commons Attribution License (http://creativecommons.org/licenses/by/4.0), which permits unrestricted use, distribution, and reproduction in any medium, provided the original work is properly cited. The Creative Commons Public Domain Dedication waiver (http://creativecommons.org/publicdomain/zero/1.0/) applies to the data made available in this article, unless otherwise stated. 